\title{
THE EXPERIENCES OF RECTAL CANCER SURVIVORS WITH STOMA IN WEST JAVA INDONESIA
}

\author{
Chandra Isabella Hostanida Purba, Kusman Ibrahim, Urip Rahayu
}

\begin{abstract}
Introduction: Important specific experience of rectal cancer survivors is how they perceive the treatment of cancer, undergo treatment completely and get healed, and live productively after recovery. The aim of the study was to obtain the significant experience of rectal cancer survivors.

Methods: This study was a qualitative phenomenological method. Sample was taken based on the snowball technique to get three individual patients. Data was collected through in-depth interview, and then was analyzed with seven steps analysis of Colazzi.
\end{abstract}

Results: A total of eight major themes that describe various experiences of the participants of rectal cancer with stoma were found, namely: difficulty in mobility/ social activity, sense of low self-esteem, pain, extra expenses, changes of patterns of sexual intercourse, dealing with loss, restrictions to worship, and the desire to share with other patients with permanent stoma. Discussion: This difficulty is drawn from the fear of lacking public facilities to support their condition, such as the place to change or unload the stoma bag/appliance, fear that the bag may produce bad odor and uncomfortable sound, purchase the bag routinely, while most of them were already unemployed, worry that the spouse feel disgusted or pity, and the uncertainty if the prayer and worship is acceptable to God.

Conclusion: life's meaning of being rectal cancer survivor helps increase the desire to share it with other patients in order to elevate their spirit amidst the same situation. Based on the stud, nurses should provide psychological support and clear information so that patients can meet their basic needs. Keywords-: cancer, life experiences, survivors

Introduction

$$
\text { Introduction }
$$

Rectal cancer is a type of cancer that attacks colon and rectum. The diagnosis of rectal carcinoma is generally easy to establish; however, sufferers are often diagnosed at an

DOI: 10.5176/2345-7198_5.1.20

ISSN 2345-7198

CThe Author(s) 2018. This article is published with open access by the GSTF

GSTF Journal of Nursing and Health Care (JNHC)

Vol.5 No.1, Apr-2018 advanced stage, thus, oftentimes curative surgery cannot be done. Rectal carcinoma is a most common malignant tumor between the digestive tract; more than $60 \%$ of colorectal tumors derived from the rectum. Although no definitive data yet, however, the data from the Ministry of Health show a rise of 1.4 per mil. [1].

Patients with rectal cancer are generally made stoma. It gives them additional duties to properly care for the stoma to prevent infection. Based on interviews with rectal cancer patients with stoma, some complaints are found, such as: patients feel low self-esteem and self-image changes; insecurity and worry about the smell of feces that come out unwittingly be smelled by other people; anxious about the feces spill when doing activities; fear of rejection by partner during sexual intercourse; fear to perform worship rituals (Sholat prayer) because of feeling unclean; limiting social activities and traveling for fear of difficulty to clean the stoma. These complaints make the patient's quality of life decreases [4].

The severity of the disease side effects and treatment makes the patients despair in life. Particularly in Indonesia, patients usually come to hospital when the cancer is already in advanced stage and the condition is very serious. They usually remedy with traditional treatment first, and then come to hospital when the condition is already critical. Thus, chemotherapy is often not successful or the patients die shortly afterwards. Some of them survive or have been declared "cured", so-called "cancer survivors". The uniqueness of life's meaning of these survivors need to be investigated as a primary data to determine adequate intervention for other cancer patients and to determine the necessity of gathering other cancer patients and forming cancer support groups, as well as primary data needed for establishing nursing home care and palliative care.

Methods 
This research uses descriptive

phenomenology,

Setting and sample

Participant taken with snowball sampling by getting three participants of rectal cancer survivors who have completed treatment in Hasan Sadikin Hospital. .

\section{Ethical consideration}

This study was conducted after obtaining approval from the Health Research Ethics Committee from Nursing Faculty Universitas Padjadjaran and Hasan Sadikin Hospital, Indonesia (Ketua komite etik penelitian kesehatan RSHS Bandung) number LB.02.01/c02/934/I/2016. In the process of recruiting participants, the researcher explained to the potential participants the details of the study. All of the participants received the information that they have the right to choose whether to participate or they may withdraw at any time without any negative consequences. The participants could convey their agreement to participate in the program verbally and/or by written consent. This research has been approved by institutional review Board (IRB) and has been conducted in accordance with accepted national and international standards; informed consent had obtained from human subjects or their guardians prior to their participations in this study. Privacy of participants is maintained, informed consent has been obtained, and potential conflict interest is disclosed. Researcher obeyed the principles of legal or formal aspects, the principles of autonomy and fairness. The principles of data validity in qualitative research were based on the following criteria: degrees of credibility, dependability, confirm ability, and transferability [8].

\section{Measurements/Instruments}

Data were collected through interviews twice in West Java in 2015-2016 used researchers as an instrument [12].

\section{Data collection/Procedure}

The data was collected at the patients' home, researcher came twice, firstly for in deep interview and the secondly to confirm the verbatim transcript.

\section{Data analysis}

\section{Colaizzi.}

Data were analyzed with technique of

\section{Results}

The research questions generate main themes that give a picture of the phenomenon or experience of the cancer survivor in treatment during illness. A total of three participants were patients who had otherwise recovered from rectal cancer after undergoing treatment in the form of colostomy surgery and chemotherapy, all of which received permanent colostomy. Patient data were obtained from medical records of Hasan Sadikin Hospital, Bandung. Majority of participants were male, as many as two people; working status: unemployed as many as two people; average age of 45 years old: the youngest was 40 years old and the oldest, 50 years old; one was diagnosed with rectal cancer since 3 years earlier, with the latest time range, 2 years, and the longest, 5 years ago. Majority of education attainment was junior high school; all participants were Islam, married, and from Sundanese ethnic.

A total of eight major themes were pointed out from the various experiences of participants. Detailed description of experiences of rectal cancer patients with stoma are presented as the following:

\section{Difficulty in Mobility}

The stories of participants were related to their experience during sickness. They told many experiences, some of which were: difficulty in mobility, traveling restriction, fear of feces spill during travel, except one participant who expressed no difficulty if he has to travel. The following are expressions of two out of three participants who told difficulty in mobility:

\footnotetext{
"I never go out, I am afraid do not find water closet to wash my stoma”.p1

'Mmm.. I am worry to make a journey, it's forcé me to bring so many equipment'.p3.

Almost all participants revealed that the colostomy had limited their activity, for fear that the stoma appliance (bag) will be
} 
easily full in the middle of the way, and finally withdraw from the social activities. The main reason for withdrawal was told by participant 2 as followed:

'I could not join social organization anymore, I just stay at home for I need special treatment in my stoma.. 'p2.

\section{Feeling low self-esteem}

Some respondents said that colostomy has made them less confident, restricted them from staying overnight in other's home. Some others said that their friends have known their situation, but they still feel uncomfortable if being seen by them. Some of their statements are:

"before this stoma, usually I having fun with my friends, but since this bag, I just stay at home, if my friends really call me to jon them, I just sat several minutes to made them happy"..p2

'Eeee.. I am shy for the first, but I can not take it longer because my neighbours already saw my stoma.. '.(pl).

Other thing made by participant to reduce

embarrassment while on outdoor activities was to limit the food intake. Some participants reduced the food and drink intake when they traveled, to avoid leaks of stoma appliance; others chose to stay hungry than to let the stoma appliance/bag being full. Below are some of the expressions:

'I limited my meals, $i$ try to keep my stoma bag not as full as possible. $(p 1)$.

\section{Pain}

Some participants complained of body pain, such as in the anus, stomach, body, etc.; however, there were participants who could still defecate through anus, as mentioned below:

'something pain in my bag, my wife always help me to reduce the pain by massage my back. '(p1).

'I feel something out from my anus, I feel pain during elimination feces" $(p 3)$

\section{Extra expenses}

All respondents expressed that they needed extra expenses to treat / take care of stoma. Generally they prepared self-made plastic bags. A respondent told that the economically he got hard up when he no longer worked.
'I feel not conform when I got diarrhea..i must changes my bag frequently, it was spent more money". p2

'I retired since last year, I have no money to buy the bag, so $i$ use other bag to carry my feces'(p1).

\section{Changes in patterns of sexual relation}

All respondents experienced changes in sexual activities. Some are afraid to do it for fear of leakage; others have fear of his partner being uncomfortable; some participants refused their spouses to have sex relations for fear of pain; some spouses feel uneasy to find comfortable position for their participant spouses; and others are afraid of being scolded by doctors. The following are some expressions of respondents:

'it's hard for me to find suitable position to having sex, it's stimulate my emotion ..(p2)

'I am getting old right now, $i$ do not need sexual aktifities anymore, if my spouse want me, I just stay above her.. '(p3) 'My husband got scarce, he do not want me feel pain because of my stoma, may be we will having seks if I am getting better ".

On the other hand, participants felt the attention of people surrounding them since getting sick, such as: family members, neighbors, or co-workers. Family members tried to make the patient always fit physically, by limiting the physical work for them. The attention of coworkers was in the form of asking "how are they doing", reminding them not to work hard. Some expressions were the following:

'My family limitate my actifity in house hold, they want me to stay cool, do not do anything'.(p1).

'my neighbours give me more helps, they help me to do my households activities.. '(p2).

'My neighbours improve my spirit, they said I must confident with my stoma bag (pl).

\section{Facing the Loss}

Participants also viewed illness as a warning from God. Generally participants assumed this pain as a rebuke from God, so it did not matter if they could not achieve their ideal self. Some participants accepted pain as a trial from God, as punishment for their sins, making them more resilient to accept and undergo treatment and quickly moving from denial to acceptance. 
'Before this stoma, I pray hardly, but now i really pray everyday may God give me the strength, .(p2)

'I am afraid to died soonly because my children still toddler, who will care of them if I died?...'(p1).

'I believe this is the test from God, may be He want me to pass this condition with brave heart'(P3).

There were also participants who had received the status of permanent stoma sincerely, although still hoping to defecate normally through anus, as revealed below:

'I want doktor reheal my stoma, I want to do my bowel elimination as normal as before this stoma..(p3).

One participant had a false conception of colostomy; he assumed that stoma can be closed, as was revealed by the participant's following statement: 'I want to stop my stoma bag soon, I do not need this stoma, the doctor will reveal my stoma...(pl).

Participants felt sad at the beginning of illness; however, ultimately they considered it as trial from God that they have to accept and endure.

"I was cry for the first 2 months, but now I know that it will be forever, hence I must be accepted this condition.. pl).

\section{Restriction to worship}

All respondents were uncomfortable to perform worship, due to assumption being defiled by the dirt that may flow continuously from stoma during worship. Meanwhile, for Muslims, worship must be done in purity, and stoma hinders them from such purity. They felt hesitant to pray, except one who continued to worship though he felt uncertain if his worship was accepted by God or not.

I rejected to eat the meals in pray time, I do not want to failure my pray if the feces out from my bag. pl).

‘... I am afraid to do pray due to my stoma

bag, I am worry my position changes during pray time will make my feces out from the bag..(p2)

.. I do not know will the God accepted my pray? I am not in Clean condition because of my feces in the stoma.. (p3).

The help of health workers gave patient enthusiasm. Respondents revealed that information, warm welcome of health professionals made them docile to follow the treatment procedures. Their sincere attention strengthened the patients. "I give thanks to the God, for I believe all the good time and bad time come from God...(p2).

\section{Desire to share with fellow sufferers}

Almost all respondents said that they really want to motivate other patients to remain steadfast, to undergo treatment until complete, to surrender and willing to follow instructions of health workers. The following statements reveal: 'I help the patients like me to make an economics bag from plastics, it can keep our money..(p2).

'I am very happy in motivating others to be struggle as me.. (p3).

\section{Discussion}

\section{Difficulty of Mobility}

The study found that all participants have been having difficulty in mobilization, including fear of stoma appliance/bag leakage when traveling, not finding toilet to clean the stoma appliance, being booed by others when there is sound and smell while traveling, or eating less while traveling. These unpleasant feelings became new stressors for patients. Consciously they often smelled the bag to make sure it did not leak. All participants used plastic bag so it was easy to leak, but they also wore stoma belt given by nurse, which they said, was more efficient and strong to support the stoma appliance/bag.

Colostomy does not have sphincter to maintain continence, so that the flow of fecal could happen at any time without control [11]. Ostomet requires adaptive coping to accept this condition. Some participants even reduce the schedule of activities and food and drink intake to prevent the flow of fecal, bad odor, flatus, which could happen at any time. When this is done constantly, the patient can have poor nutrition, infections and other complications. Based on the study of [10] on 48 
stoma patients, $35(73 \%)$ stated no skin problems, but overall: 27 patients had skin disorder and 13 were detected by stoma nurses to have skin erosion.

\section{Feeling low self-esteem}

Colostomy has made them less confident, restricted from staying at other people's home. Some respondents said that their friends already knew their condition but still felt embarrassed when friends saw it, even felt 'numb' to eat because of being disgusted at their own stoma. Other participants had to starve when they participated in an activity to prevent flatus.

This shows how important a sense of self-acceptance and the acceptance surrounding people or community to the patient's condition. Failing to do so can fail the patient. The stigma that being closer with stoma patient is disgusting, losing appetite, must be eradicated. both ostomet and the environment must learn to accept this condition as something natural. The condition of public facilities in Indonesia has not been so good, where it is difficult to find really clean toilet. It becomes the factor that hinders ostomet to travel out of fear of not finding clean toilet to change appliance or to fix it when leaks may occur.

Based on the research of [9], most colostomy patients $(58.33 \%)$ have negative body image after colostomy intervention. Participants of this study were finally declared cured in spite of being with a permanent stoma. That means they will treat stoma for a lifetime; thus self-acceptance must be nurtured as early as possible in order to be able to adapt to new life situation. It is important to have supporting community as a venue where they can share life's experiences, as well as reachable supporting facilities for them while being outside the home[7]. Any assistance to modify selfimage can be given to strengthen patient's initiative in achieving personal goals; what is more important is compliance to it. Patients should also be encouraged to take responsibility in reducing non-compliant behavior, such as boredom, laziness and others [15].

3. Pain

Some participants complained of body pains, such as, in the anus, stomach. Meanwhile, a patient can still defecate through anus. Participants did sport to reduce pain, though its portion was lesser and its method changed. The pain was felt while treatment, and slowly disappeared as treatment completed. Pain is objective. In some cancer patients, pain is not felt so heavy, but some say that pain has reduced their quality of life; they cannot sleep well, eating, resting, working well, and they feel good only upon taking morphine. Thus, intervention to reduce pain in cancer patients should be given to help improve their quality of life. The meaning of pain to cancer patients has to be understood as a plea for help to health professionals. How to manage pain is very important to new patients.

\section{Extra funds}

All respondents said that they need extra expenses to care for stoma. Generally they used home-

made stoma appliances One

respondent felt increasingly

burdensome due to increase cost of sustenance, since he did not work anymore. Diarrhea and bag leakage is the biggest reason for additional costs to swell.

At this time the whole Indonesian people already have access to health insurance through the use of social security system (BPJS). The law on BPJS determines that it functions to organize health insurance program. According to the Social Security Law, the insurance system is organized based on the principle of 
insurance and equity, with the goal to guarantee that all members get health care and protection to meet basic health needs. [5] With this system, a permanent stoma cancer patient can have easy access to get stoma appliances/bags from health centers so as to reduce personal out of pocket expenses.

Additional expenses of ostomet means forcing them to be prudent in spending and preventing them from spending on things unnecessary. For those who have extra income, there seems to be no problem. However, those with low income, they are prone to infections and irritations due to lack of hygienic personal home-made bags from sugar plastics and irritating doubletip adhesive

\section{Changes in patterns of sexual}

\section{intercourse}

All respondents experienced changes in sexual patterns. Some were afraid to do it due to the fear of leakage, feeling uncomfortable of spouses, being refused by the spouse to avoid pain, difficulty of finding comfortable position, or for fear of being scolded b physician.

In general, the Indonesian people still consider sex life as a personal thing; not a main thing that must be satisfied. So it is rarely a problem for the couple. Generally the spouses can understand and accept the condition of their partners, and less likely to demand sexual satisfaction from their partners publicly. They tend to say that every the partner being offended. Sex problem is indeed a personal thing for Indonesians in general; thus, it needs suitability and adjustment to Indonesian culture in giving solutions and recommendations. Openness of patients and their spouses since the beginning of treatment regarding sexual life and satisfaction should be discussed and settled properly.

Attention to patients can
foster self-confidence and self-

esteem. Patients can feel being needed, and it motivates them to improve their health. Moreover, the communal or collective culture of Indonesia encourages each patient to share the joys and pains together; invokes the awareness of feeling, thinking, and acting together based on conscience to share the difficulties of each other; and depending on each other [14]. If the community considers the patient as important, the patient can continue the treatment with enthusiasm. Based on this phenomenon, the patient needs a community and environment that continues to accept and support him to move forward.

\section{Faced with loss}

Participants assumed illness as a rebuke from God, so it did not matter if they cannot achieve the ideal self. Some participants accepted it as a trial from God, as a recompense of sins, thus, making them more resilient to accept and undergo treatment and quickly moved from denial to acceptance phase. Losing was a common experience that everyone can face in the span of life [13].

The meaning of loss for the participants is a normal response, such as the loss of body functions, disfigure of physical image especially for those who put weight on physical appearance. One of the Islamic patient's attitude in Indonesia is a sense of surrender, i.e., an understanding that everything in this life is temporary; one day everything will loss; all changes are trials from God which has to be accepted; do not demand too much to God for the sufferings and human limitations; and that all trials are meant to purify human intentions and a form of worship to God.

\section{Limitations of worship}

All participants feel uncomfortable to perform worshiping rituals such as prayer and going to the Mosque based on the assumption of 
being defiled by impurities from continuous flow of dirt or fecal. Meanwhile for Muslims, worship must be done in the state of purity, free from defilement, for otherwise, it could become hindrance. A participant, however, continuous to perform worship despite the uncertainty if his prayers are accepted by God or not.

Worshiping performed as worship is a term that covers all that God loves and blesses, whether in speech or deed, the Zahir and the spiritual. Worshiping is divided into the worship of heart, mouth and body. The sense of Khauf (fear), raja '(hope), mahabbah (love), tawakkal (dependence), raghbah (happy), and rahbah (fear) are the worships of qalbiyah (relating to the heart). While the beads, tahlil, Takbir, tahmid and gratitude with the mouth and heart are worship lisaniyah and qalbiyah (mouth and heart). While, prayers, alms, pilgrimage, and jihad are physical forms of worship (physical and heart). And there are many other kinds of worship relating to the practice of heart, mouth and body. To be acceptable to God, true worship is required. And a true worship has to fulfill at least two conditions, namely: sincerely for Allah alone; free from major and minor syirik, Ittiba - in accordance with the guidance of the Prophet sallallaahu' alaihi wa sallam. [2].

\section{Desire to share with others who}

suffer.

Almost all respondents said that they wanted to motivate other patients to remain steadfast, to undergo treatment completely, to surrender and willing to follow instructions of health professionals. On the other hand, the help of health professionals elevated the spirit of patients. Interestingly, all respondents wore stoma belt from a nurse in the stoma ward of RSHS. All of them expressed satisfaction and contentment with the appliance due to its durability, inexpensive and being strong. These explain that the attitude of nurses in evidence-based practice indicates that there is a significant relationship between the training provided to nurses on the quality of nurses' attitude in stoma care.

The study on the good stoma appliance product shows that the quality of life of patient increases upon using good technological products that can reduce smell, sound, leakage, and risk of infection ([3].

\section{Conclusion}

Based on the results of this study, it can be concluded that there is a meaning in life of rectal cancer survivors with stoma, as represented by eight themes, namely: mobilization / social activities, feelings of low self-esteem, Pain, Extra expenses, changing pattern of sexual relations, facing with loss, worship restrictions, desire to share with others who suffer.

The results of study show that some patients still have false conception and presumptions of permanent stoma. They thought that it can still recover to normal condition as previous situation before stoma. Thus, the nurse should design programs to help improve knowledge of patients and their compliance in taking care of stoma. In addition, there must be effort to create comfortable, affordable and durable stoma belt for patients which can help increase their sense of selfworth. Further study is needed to discover deeper the experience of patients in relation to sexual life satisfaction, especially to identify various factors related to the lack of understanding of sexual intercourse positions, patient behavior in taking care of stoma, and to identify the special needs of patients in regards to their basic needs. 
1. Riset Kesehatan dasar [ Basic Health Research] [Internet]. depkes RI. 2013 [cited 2016 Nov]. Available from: http://www.depkes.go.id/resources/do wnload/general/ Hasil\%20Riskesdas\%202013.pdf.

2. Jawas A-UYbAQ. 2016 November

3. Dika A. Menejemen kolostomi. [Kolostomi Management] kompasiana. 2016.

4. Gooszen A, Geelkerken, RH, Hermans, J, Lagsay, MB, Gooszen,, HG. Quality Of Life With A Temporary Stoma: Ileostomy Vs. Colostomy. Deseases Colon Rectum 2000;43 (5):650-5.

5. Indonesia J. BPJS. [ Indonesian Health Insurance]. 2016. p. 268.

6. Karadag A, Mentes, B.B, Uner, A, Irkorucu, O, Ayaz, S, Ozkan, S. . Impact Of Stoma-Therapy On Quality Of Life In Patients With Permanent Colostomies Or Ileostomies. Journal of Colorectal Diseases. 2002;18(3):234-8.

7. Kozier B, et all. Fundamental Of Nursing: Concepts, Process \& Practice. 7th ed. Upper Saddle River: Pearson Education Inc

2004.

8. Moleong LJ. Qualitative Research Methodology 2011.

9. Panusur NH. Kemampuan Self-care and Self-ability Patiens with colostomy di Adam Malik Medan Hospital 2016.

10. Piccinellil M BR, and Saracco C. Assessment Of The Prevalence And Perception Of Skin Problems In Patients With Permanent Stoma. Journal Article Country of Publication: Nursing. 2009;28( 4 ):183-9. PubMed Central PMCID: PMC20222519.

11. Smeltzer Be. Text book of Medical Nursing. 2014.

12. Streubert HJC, D.R. Qualitative Research In Nursing Advancing The Humanistic Imperative. 2013.

13. Sundeen Sa. Psychiatric Nursing Handbook,: ECG; 2013.
14. Prawoto K. Communal Society. Kompasiana. 2016.

15. Wilkinson J. Nursing Diagnosis Handbooks with NIC Interventions \& NOC Outcomes. 2005. 